$5-1-2020$

\title{
Occurrence and Mass Loading of Synthetic Opioids, Synthetic Cathinones, and Synthetic Cannabinoids in Wastewater Treatment Plants in Four U.S. Communities
}

Catherine O'Rourke

Murray State University, corourke@murraystate.edu

Bikram Subedi

Murray State University, bsubedi@murraystate.edu

Follow this and additional works at: https://digitalcommons.murraystate.edu/faculty

\section{Recommended Citation}

O'Rourke, Catherine and Subedi, Bikram, "Occurrence and Mass Loading of Synthetic Opioids, Synthetic Cathinones, and Synthetic Cannabinoids in Wastewater Treatment Plants in Four U.S. Communities" (2020). Faculty \& Staff Research and Creative Activity. 90.

https://digitalcommons.murraystate.edu/faculty/90

This Journal Article is brought to you for free and open access by Murray State's Digital Commons. It has been accepted for inclusion in Faculty \& Staff Research and Creative Activity by an authorized administrator of Murray State's Digital Commons. For more information, please contact msu.digitalcommons@murraystate.edu. 


\title{
Occurrence and Mass Loading of Synthetic Opioids, Synthetic Cathinones, and Synthetic Cannabinoids in Wastewater Treatment Plants in Four U.S. Communities
}

\author{
Catherine E. O’Rourke and Bikram Subedi*
}

Cite This: Environ. Sci. Technol. 2020, 54, 6661-6670

Read Online

ACCESS | Lill Metrics \& More | 回 Article Recommendations ｜ sl Supporting Information

ABSTRACT: A few new psychoactive substances (NPS) that mimic the effects of controlled neuropsychiatric and illicit drugs have been forensically identified in the U.S. Wastewater-based epidemiology (WBE) can provide a comprehensive and more cost- and time-effective method of determining the prevalence of NPSs in communities. In this study, an analytical method capable of simultaneous determination of trace-level 40 NPS residues (synthetic opioids, synthetic cannabinoids, synthetic cathinones, piperazines, indole, and amphetamine) in wastewater was developed and validated. The developed analytical method was utilized to determine the occurrence of NPSs in four rural communities in southern Illinois. Nine NPSs (carfentanil, furanyl fentanyl, methoxyacetyl fentanyl, MAB-CHMINACA, methcathinone, 4-methyl pentedrone, 2-methyl-4'-(methylthio)-2-morpholinopropio-

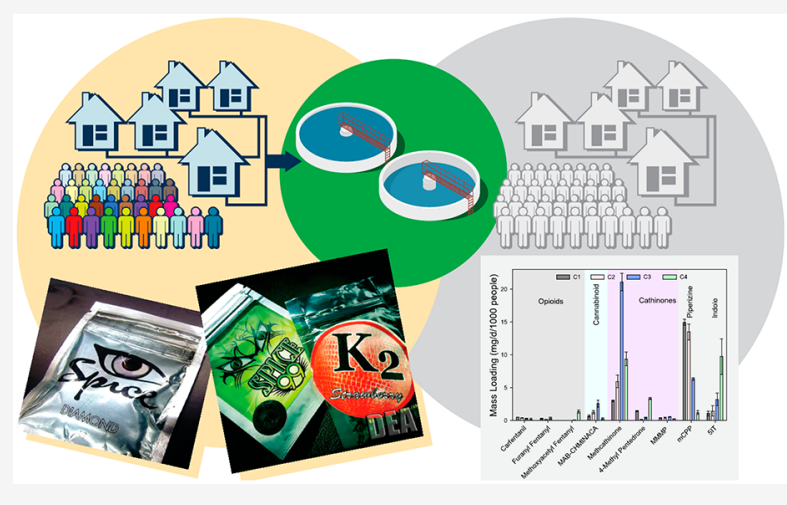
phenone (MMMP), 1-(3-chlorophenyl) piperazine (mCPP), and 5-(2Aminopropyl) Indole (5IT) were quantified. Methcathinone was the most frequently detected NPS (detection frequency, df = $100 \%)$ followed closely by the MMMP and mCPP ( $\mathrm{df}=91 \%)$. The mass loading of methcathinone, mCPP, and 5-IT using ammoniacal nitrogen-based population were up to $21.1 \pm 1.3 \mathrm{mg} / \mathrm{d} / 1000$ people, $15.0 \pm 0.5 \mathrm{mg} / \mathrm{d} / 1000$ people, and $9.75 \pm 2.72$ $\mathrm{mg} / \mathrm{d} / 1000$ people, respectively. This is the first study to determine the occurrence of NPSs including synthetic opioids, synthetic cannabinoids, synthetic cathinones, and piperazines in the U.S. communities.

\section{INTRODUCTION}

New narcotics or psychoactive substances (NPS) in "pure" or "preparation" forms are created to have the similar effects of established prescribed and illicit neuropsychiatric drugs. ${ }^{1}$ There were $\sim 500$ NPS in the global market each year from 2015 to $2017 .^{2}$ In the U.S., the forensic identifications of NPS tripled from 684 identifications in 2016 to 2023 identifications including 1783 opioids/analgesics, 81 synthetic cannabinoids, 55 synthetic cathinones, 46 benzodiazepines, and 58 "others" in 2019. ${ }^{3}$ There were five NPS (carfentanil, furanyl fentanyl, 5fluoro $\mathrm{AMB}$, 5-fluoro $\mathrm{ADB}$, and Nethylpentylone) among 25 most prevalent drugs in the Midwest in $2017 .{ }^{4}$ National Drug Early Warning System (NDEWS) reported 3099 counts of fentanyl, 670 counts of synthetic cathinones, and 633 counts of synthetic cannabinoids seizures in 2017 in Illinois by the law enforcement. $^{5}$

The NDEWS has reported the prevalence of NPS based on the forensic analyses, which can underestimate the actual amount of abused drugs and cause a delay between the outbreak of a drug and the intervention of law enforcement. Wastewater-based epidemiology (WBE) provides a noninvasive, comprehensive, cost-effective, and near-real-time estimation of the prevalence of substance use in a community. ${ }^{6-8}$ WBE has recently been demonstrated as a complementary tool to a forensic toxicological approach to comprehend a trend in the consumption of NPS in Australia. ${ }^{9}$ NPSs are reintroduced in markets in quick succession to impede the law enforcement's efforts to control NPS production and purchases. ${ }^{1}$ Therefore, the traditional approaches are not suitable for drug monitoring, surveillance, control, and the immediate responses to the harm associated with the NPS. ${ }^{10,11}$ WBE can be used as a proactive public health surveillance system for NPS for prompt intervention. In $\mathrm{WBE}$, the residual parent drugs or their metabolites in raw wastewater are utilized to back-calculate the prevalence of target drugs in a community.

NPS typically are more potent and toxic than established drugs of abuse, such as illicit drugs and prescribed opioids. Carfentanil, a synthetic opioid, is $\sim 100$ folds more potent than

Received: January 13, 2020

Revised: May 1, 2020

Accepted: May 1, 2020

Published: May 1, 2020 
fentanyl and $\sim 10000$ folds more powerful than morphine. Synthetic cannabinoids mimic the psychotropic effects of cannabis-derived cannabinoids (e.g., $\Delta^{9}$-tetrahydrocannabinol: THC) binding similarly to the cannabinoid receptors; however, synthetic cannabinoids are more potent and efficacious cannabinoid receptors antagonists than THC. ${ }^{12}$ Similarly, 3,4-methylenedioxypyrovalerone, a common synthetic cathinone, has similar effects as cocaine but $\geq 10$ folds more powerful than cocaine. ${ }^{1}$ Therefore, the potential ultratrace level of NPS in wastewater, a complex environmental matrix, poses analytical challenges for the detection and quantification. NPS in wastewater typically have been enriched using solidphase extraction (SPE) and analyzed using a high-performance liquid chromatography tandem mass spectrometric technique (HPLC-MS/MS) for target quantification ${ }^{13-15}$ as well as Orbitrap high resolution mass spectrometer ${ }^{16,17}$ and time-offlight mass spectrometer ${ }^{18-20}$ for target and untargeted screening. The majority of the reports used either neutral HLB (hydrophilic-lipophilic balance) or mix mode cationexchange cartridges (MCX or WCX) for the quantification of few NPSs of a particular class of drugs, such as synthetic cannabinoids or synthetic cathinones. Typically, nonacidified wastewater samples were extracted via the preconditioned HLB cartridge (with methanol followed by water) and eluted with methanol; ${ }^{17,21}$ however, acidified $(\mathrm{pH} \sim 2-5)$ wastewater samples were extracted via the preconditioned MCX cartridge (with methanol followed by acidified water) and eluted with methanol followed by ammoniacal methanol $(\sim 2$ or $5 \%)^{16,17,22}$

Bade et al. $^{23}$ found MCX-extraction more efficient than HLB-extraction for synthetic cathinones whereas Fontanals et al. $^{16}$ preferred WCX over MCX for synthetic cathinones. To the authors' knowledge, there was no report of the optimized extraction of synthetic fentanyls from wastewater. SalgueroGonzalez et al. ${ }^{16}$ used both HLB and MCX cartridges to cover the wide range of physio-chemical properties of NPSs including synthetic cathinones and synthetic cannabinoids. All WBE studies on NPS have focused on synthetic cannabinoids and synthetic cathinones. To our knowledge, there are no reports of simultaneous quantification of synthetic cathinones, synthetic cannabinoids, and synthetic opioids in wastewater. The prevalence of NPS in communities using WBE have been reported in Europe ${ }^{11,13,17,24}$ Australia, ${ }^{9,23}$ and China. ${ }^{22}$ However, this is the first study of reporting NPSs in wastewater in the U.S.

In this study, an analytical method capable of simultaneous trace-level determination of 40 NPS residues including 11 synthetic cannabinoids, 10 synthetic cathinones, 15 synthetic opioids, 2 piperazines, 1 indole, and 1 amphetamine in wastewater has been developed and validated. The occurrence of NPS in four rural southern communities in Illinois was determined based on the level of NPSs measured for seven consecutive days. Moreover, clonazepam (benzodiazepine,) and gabapentin (anticonvulsant) were also determined as a potential chemical marker of NPS prevalence in target communities owing to the regional potential abuse. ${ }^{25}$

\section{MATERIALS AND METHODS}

Reagents and Chemicals. Based on the frequent forensic identifications of NPS by the NDEWS in the U.S., ${ }^{3-6} 40$ NPS were selected belonging to opioids/analgesics, synthetic cannabinoids, synthetic cathinones, piperazines, indoles, and amphetamines. Target drugs include opioids/analgesics: carfentanil, furanyl fentanyl, valeryl fentanyl, butyryl fentanyl, acetyl fentanyl, cyclopropyl fentanyl, benzyl fentanyl, $3^{\prime}$-methyl fentanyl, 4'-methyl acetyl fentanyl, 4-fluoro-isobutyryl fentanyl, para-fluorobutyryl fentanyl, methoxyacetyl fentanyl, 4-ANPP, U-48800, U-47700; synthetic cannabinoids: 5-fluoro MDMBPICA, MAB-CHMINACA, MMB-FUBINACA, 5-fluoro EDMB-PINACA, (R)-5-fluoro ADB, AB-FUBINACA, MMBCHMICA, AB-CHMINACA, ADB-FUBINACA, 5-fluoro AMB, NM2201; synthetic cathinones: ( \pm )-methcathinone, ethylone, 4-MMC/mephedrone (MMC), 4-methyl pentedrone, $N$-ethylpentylone, $\alpha$-pyrrolidinopropiophenone, 3,4methylenedioxypyrovalerone, $\alpha$-ethylaminohexanophenone, 2 methyl-4'-(methylthio)-2-morpholinopropiophenone, 4chloro- $\alpha$-PVP; piperazines: 1-(3-chlorophenyl) piperazine (mCPP), 1-cyclohexyl-4-(1,2-diphenylethyl) piperazine (MT45); indole: 5-(2-aminopropyl) indole (5IT); amphetamine: 4methylamphetamine. Target drugs also include two of the most commonly used anticonvulsants in the U.S. gabapentin and clonazepam.

High purity standard solutions $(50,100$, or $1000 \mu \mathrm{g} / \mathrm{mL})$ or solids ( 1 or $5 \mathrm{mg}$ ) of each target drug and the corresponding deuterated internal standards (carfentanil- $\mathrm{d}_{5}$, furanyl fentanyl $-\mathrm{d}_{5}$, valeryl fentanyl- $\mathrm{d}_{5}$, butyryl fentanyl- $\mathrm{d}_{5}$, acetyl fentanyl $-{ }^{13} \mathrm{C}_{6}$, cyclopropyl fentanyl- $\mathrm{d}_{5}$, 4-fluoro-isobutyryl fentanyl- $\mathrm{d}_{7}, 4^{\prime}$ methyl acetyl fentanyl- $\mathrm{d}_{5}$, methoxyacetyl fentanyl- $\mathrm{d}_{5}$, 4ANPP- $d_{5}$, MAB-CHMINACA- $d_{4}, \quad$ U-48800- $d_{3}, \quad$ U-47700- $d_{3}$, AB-FUBINACA- $d_{4}$, N-ethylpentylone- $d_{5}$, methcathinone- $d_{3}$, ethylone- $\mathrm{d}_{5}$, mephedrone- $\mathrm{d}_{3}$, 3,4-methylenedioxypyrovalerone- $\mathrm{d}_{8}$, mCPP- $d_{8}$, MT45- $\mathrm{d}_{11}$, gabapentin- $\mathrm{d}_{10}$, clonazepam- $\mathrm{d}_{4}$ ) were purchased from Cerilliant (Round Rock, TX) or Cayman Chemical (Ann Arbor, MI) and stored at $-20{ }^{\circ} \mathrm{C}$. HPLC grade methanol and formic acid (99.5\% purity) were purchased from Fisher Scientific (Hampton, NH), hydrochloric acid and ammonium hydroxide were purchased from Pharmco (Brookfield, CT), and ultrapure water was prepared with Barnstead Ultrapure System.

Sample Collection. Samples from four WWTPs in four rural counties in Southern Illinois (C1, C2, C3, and C4) were collected for seven consecutive days during a typical week with no special events (to the best of our knowledge) in early August of 2019. An aliquot of untreated wastewater was withdrawn every 15 min using a time-proportional autosampler for $24 \mathrm{~h}$, composited, and stored at $4{ }^{\circ} \mathrm{C}$. However, grab samples were collected from $\mathrm{C} 4$ around noon due to the unavailability of an autosampler. The week-average wastewater inflow in C1, C2, C3, and C4 were $0.70 \pm 0.10,1.77 \pm 0.38$, $2.64 \pm 0.19$, and $0.47 \pm 0.04$ million gallons per day, respectively. All samples were collected in one-liter polypropylene bottles, transported on ice to the laboratory, stored at $-20{ }^{\circ} \mathrm{C}$, and extracted within $48 \mathrm{~h}$.

Sample Preparation. One hundred milliliters of acidified $(\mathrm{HCl}, \mathrm{pH} \sim 2)$ raw wastewater in duplicates $(n=2)$ for each of the four sites were centrifuged at $4500 \mathrm{rpm}$ for $5 \mathrm{~min}$ and filtered under vacuum using $0.45 \mu \mathrm{m}$ white nylon filter paper to separate suspended particulate matter. The wastewater samples were spiked with 50 or $100 \mathrm{ng}$ of internal standards, mixed well, and extracted using Oasis MCX 6 cc solid-phase extraction cartridge. Before extraction, cartridges were conditioned with $3.0 \mathrm{~mL}$ of methanol followed by $3.0 \mathrm{~mL}$ of acidified ultrapure water (formic acid, $\mathrm{pH} \sim 2$ ). The samples were extracted at a rate of $\sim 1 \mathrm{~mL} / \mathrm{min}$, dried under vacuum for $\sim 5 \mathrm{~min}$, eluted with $5.0 \mathrm{~mL}$ of $5 \%$ ammonia in methanol, and stored at $-20{ }^{\circ} \mathrm{C}$. The eluate was concentrated to $\sim 250 \mu \mathrm{L}$ 
x103 Cpd 19: EAHP 10.96: +ESI MRM Frag=135.0V CID@10.0 $(220.1 \rightarrow 202.1)$ MS.d

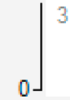

$\alpha$-Ethylaminohexanophenone

0

$x 10^{3}$ Cpd 21: MDPV 11.39: +ESI MRM Frag=135.0V CID@27.0 (276.1 -> 135.0) MS.d

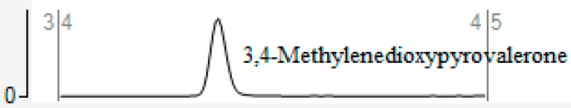

x10 3 Cpd 22: PVP 11.95: +ESI MRM Frag=135.0V CID@23.0 (266.1 > 125.0) MS.d

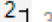

$2-3 \mid 4$

$0-$

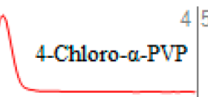

Frag=135.0 $\mathrm{CID}$ C22.0 (3532 ->

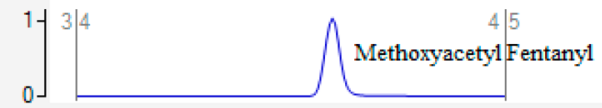

x10 4 Cpd 26: ACF 12.55: +ESI MRM Frag=135.0V CID@22.0 (323.2 -> 188.0) MS.d

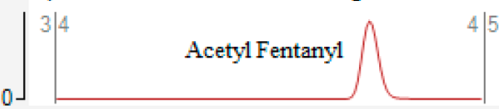

x10 3 Cpd 29: U477 12.87: +ESI MRM Frag=135.0v CID@18.0 (329.1 > 284.0) MS.d

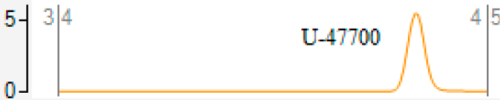

104 Cpd 30: ANPP 12.91: +ESI MRM Frag=135.0V CID@14.0 (281.1 > 188.1) MS.d

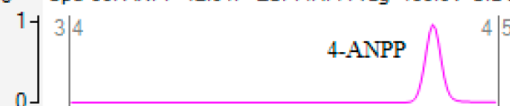

$10^{4}$ Cpd 32: BZF 13.94: +ESI MRM Frag=135.0V CID@22.0 (323.2 -> 174.1) MS.d

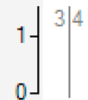

Benzyl Fentanyl

04 Cpd 33: MAF 14.00: +ESI MRM Frag=135.0V CID@22.0 (337.2 -> 202.1) MS.d

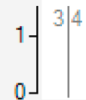

4'-Methyl Acetyl Fentanyl

x10 3 Cpd 36: U488 14.15: +ESI MRM Frag=135.0V CID@15.0 (343.0 -> 298.0) MS.d

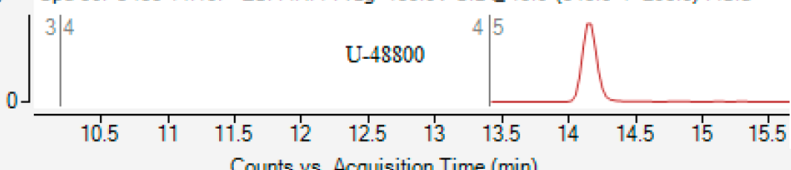

x10 3 Cpd 58: ABC 20.35: +ESI MRM Frag=135.0V CID@14.0 (357.1 > 312.1) MS.d

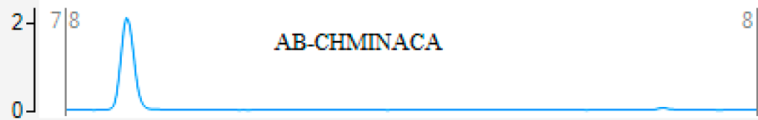

104 Cpd 59: MDMB 20.41: +ESI MRM Frag=135.0V CID@10.0 (377.1 > 232.0) MS.d

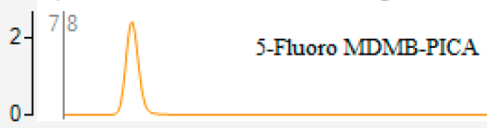

x10 4 Cpd 60: FAMB 20.74: +ESI MRM Frag=135.0V CID@22.0 (364.1 $>233.0)$ MS.d

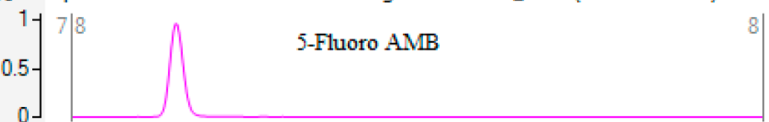

x10 4 Cpd 61: MMBF 21.06: +ESI MRM Frag=135.0V CID@11.0 (384.1 > 324.1) MS.d

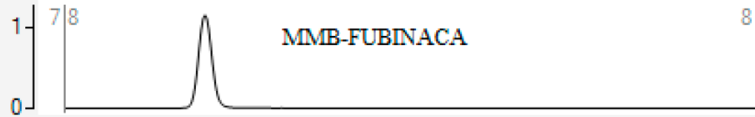

x10 2 Cpd 63: MABC 21.18: +ESI MRM Frag=135.0V CID@8.0 (371.1 -> 326.0) MS.d

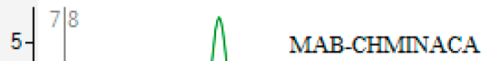

3 Cpd 64: RADB 21.70: +ESI MRM Frag=135.0V CID@16.0 (378.2 > 318.1) MS.d

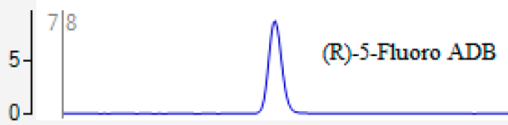

10 4 Cpd 65: MMBC 21.99: +ESI MRM Frag=135.0V CID@14.0 (371.1 > 240.0) MS.d

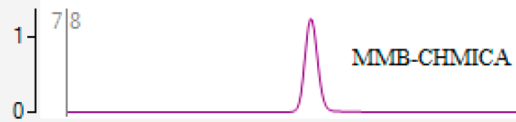

x10 4 Cpd 66: EDMB 22.53: +ESI MRM Frag=135.0V CID@9.0 (392.1 -> 318.2) MS.d

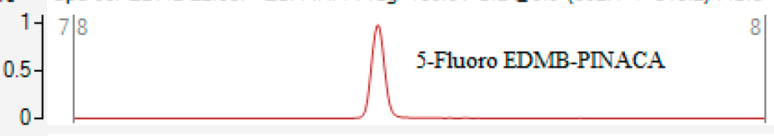

$x 10^{3}$ Cpd 67: NM2201 25.23: +ESI MRM Frag=135.0V CID@5.0 (376.1 $\left.\rightarrow 232.0\right)$ MS.d

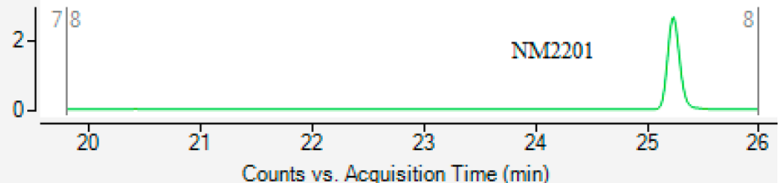

Figure 1. Schematic diagram showing the chromatographic separation of select drugs in a drug-spiked (50 or 100 ng) wastewater extract. All other target drug's chromatograms are presented in SI Figure S1.

under a gentle flow of nitrogen gas at ambient conditions. The concentrate was transferred quantitatively to an amber silanized LC vials and the final volume was adjusted to $\sim 1.0$ $\mathrm{mL}$ with methanol. One microliter of all prepared samples was subjected to the instrumental analysis.

Instrumental Analysis. Ultrahigh-performance liquid chromatography (Agilent 1290 Infinity II LC System) was coupled with tandem mass spectrometry (Agilent 6460 triple quadrupole mass spectrometer) (Santa Clara, CA) to analyze the prepared samples for target drug residues. Target analytes were chromatographically separated (Figure 1, Supporting Information (SI) Figure S1) by using a Force Biphenyl column $(100 \mathrm{~mm} \times 2.1 \mathrm{~mm}$ i.d. $\times 1.8 \mu \mathrm{m}$ particle size $)$ and the gradient flow of HPLC-grade methanol and $0.1 \%$ aqueous solution of formic acid (SI Table S1). Relative retention time ( $\pm 0.05 \mathrm{~min})$ to their deuterated forms, two parent-to-daughter ion transitions (SI Table S2), and the ratio of the abundance of quantitative to qualitative ions $( \pm 20 \%)$ were used for target analyte peak identification. The collision energy for multiple reaction monitoring transitions were optimized for all analytes and internal standards (SI Table S2). The source parameters including gas temperature $\left(330^{\circ} \mathrm{C}\right)$, gas flow rate $(5 \mathrm{~L} / \mathrm{min})$, nebulizer (30 psi), sheath gas temperature $\left(250{ }^{\circ} \mathrm{C}\right)$, sheath gas flow rate $(12 \mathrm{~L} / \mathrm{min})$, and capillary voltage $(4000 \mathrm{~V})$ were used.

Analytes were quantified using the isotopic dilution mass spectrometry method where a known quantity of deuterated isotopes of drugs was spiked into the sample prior to sample preparation. This method corrects for the loss of analytes during the sample preparation and instrumental analysis. However, closely related deuterated internal standards from the same class and or adjacent retention times were used for the quantification of select drugs that were not commercially available. Valeryl fentanyl- $\mathrm{d}_{5}$ was used as an internal standard for 2-methyl-4'-(methylthio)-2-morpholinopropiophenone, cyclopropyl fentanyl- $\mathrm{d}_{5}$ for $3^{\prime}$-methyl fentanyl, 4-fluoro-isobutyryl fentanyl- $\mathrm{d}_{7}$ for para-fluorobutyryl fentanyl, $4^{\prime}$-methyl acetyl fentanyl- $d_{5}$ for benzyl fentanyl, methoxyacetyl fentanyl- $d_{5}$ for 


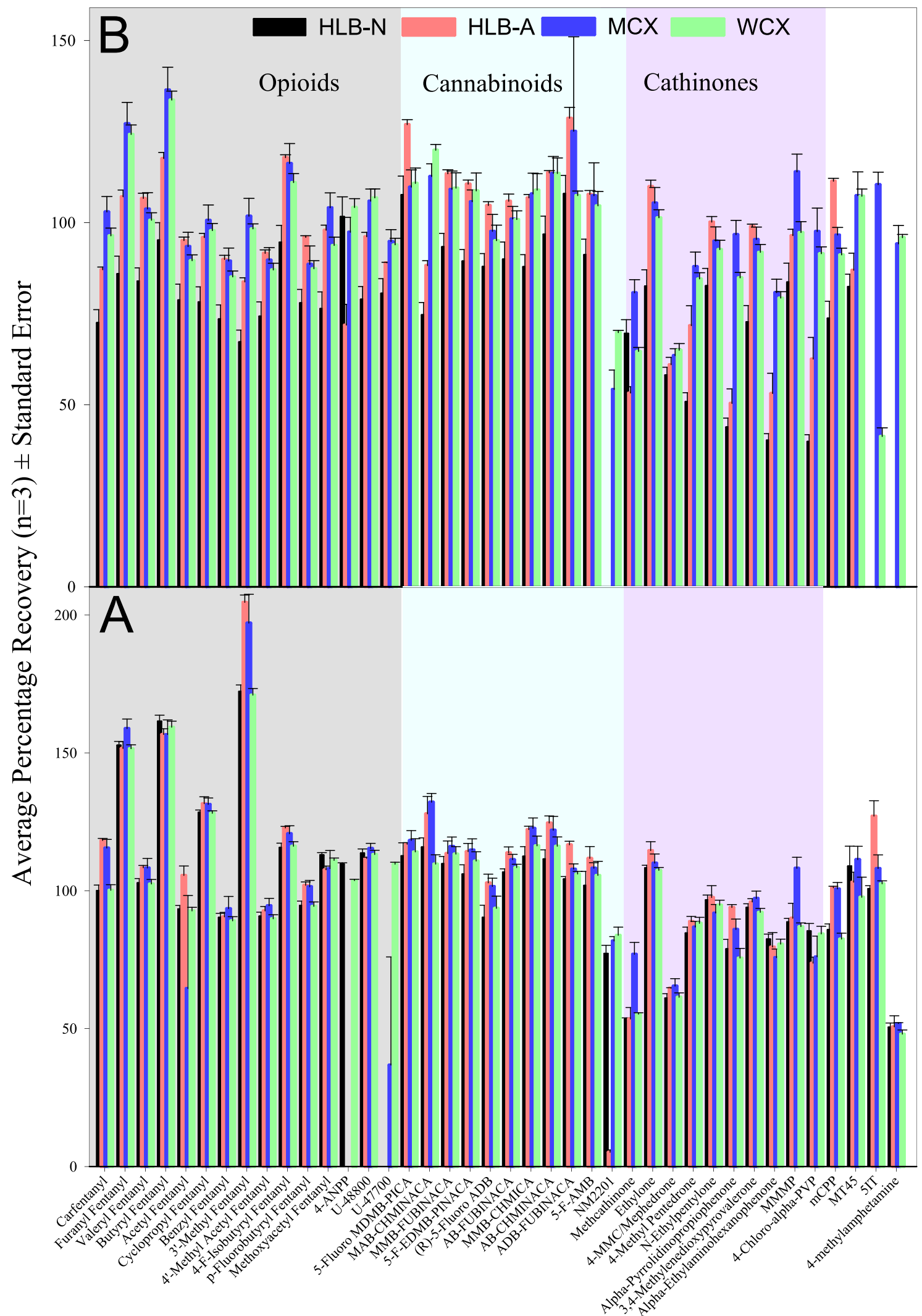

Figure 2. Absolute spiking recoveries of target NPSs $(n=3)$ at (A) 50 or $100 \mathrm{ppb}$ and (B) 2 or 4 ppb using HLB-N (pH $\sim 7$ sample using HLB), HLB-A ( $\mathrm{pH} \sim 2$ sample using HLB), MCX, and WCX cartridges. mCPP: 1-(3-chlorophenyl) piperazine; MMMP: 2-methyl-4'-(methylthio)-2morpholinopropiophenone; 5IT: 5-(2-aminopropyl) Indole.

4-chloro- $\alpha$-PVP, MAB-CHMINACA- $d_{4}$ for 5-fluoro MDMBPICA, MMB-FUBINACA, 5-fluoro EDMB-PINACA, (R)-5fluoro $\mathrm{ADB}, \mathrm{MMB}-\mathrm{CHMICA}, \mathrm{AB}-\mathrm{CHMINACA}$, 5-fluoro
AMB, and NM2201, AB-FUBINACA- $d_{4}$ for ADB-FUBINACA, $N$-ethylpentylone- $\mathrm{d}_{5}$ for 4-methyl pentedroneand $\alpha$ ethylaminohexanophenone, methcathinone- $d_{3}$ for 5IT, and 
ethylone- $\mathrm{d}_{5}$ for $\alpha$-pyrrolidinopropiophenone and 4-methylamphetamine. The concentration-dependent response factor was plotted against the response-dependent concentration factor to produce a nine-to-12-point calibration curve for each target drug. The regression coefficients calculated by linear or quadratic regression were $r^{2} \geq 0.99$ for all target analytes. All quantitate analysis was performed using Mass Hunter Version 10.0 .

Optimization of Extraction Efficiency. Oasis HLB (6 cc, $200 \mathrm{mg}$ ), MCX (6 cc, $150 \mathrm{mg}$ ), and WCX (6 cc, $150 \mathrm{mg}$ ) solid-phase extraction cartridges and different extraction eluents were evaluated for the optimum simultaneous extraction of target drugs. Hydrophilic-lipophilic balance (HLB) are broad-spectrum cartridges and ideal for acidic, basic, and neutral analytes. Mixed-mode, strong cationexchange (MCX) cartridges are selective for bases with organic solvents, whereas weak cation-exchange (WCX) cartridges are mixed-mode and used for strong bases with organic solvents. ${ }^{26}$ In this study, absolute spiking recoveries $(n=3)$ were determined at a lower spiking level $(2.0$ or $4.0 \mathrm{ng})$ as well as midpoint calibration level (50 or $100 \mathrm{ng}$ ).

The HLB cartridges were conditioned with $3.0 \mathrm{~mL}$ of methanol followed by $3.0 \mathrm{~mL}$ of ultrapure water to extract nonacidified $(\mathrm{pH} \sim 7)$ filtered wastewater. The extraction recovery of target drugs from HLB cartridges was also evaluated in acidic conditions (HLB-A), conditioned using $3.0 \mathrm{~mL}$ of methanol followed by $3.0 \mathrm{~mL}$ of acidified ultrapure water (formic acid, $\mathrm{pH} \sim 2$ ) and extracted the acidified wastewater. All HLB cartridges were dried under vacuum for $\sim 5 \mathrm{~min}$, and eluted with $5.0 \mathrm{~mL}$ of $2 \%$ ammonia in methanol, as reported elsewhere. ${ }^{21,24}$

The MCX cartridges were conditioned with $3.0 \mathrm{~mL}$ of methanol followed by $3.0 \mathrm{~mL}$ of acidified ultrapure water (formic acid, $\mathrm{pH} \sim 2$ ), used to extract $\sim 100 \mathrm{~mL}$ of acidified wastewater, dried under vacuum, and eluted with $5.0 \mathrm{~mL}$ of $5 \%$ ammonia in methanol. However, WCX cartridges were conditioned with $3.0 \mathrm{~mL}$ of methanol followed by $3.0 \mathrm{~mL}$ of ultrapure water, extracted nonacidified $(\mathrm{pH} \sim 7)$ wastewater, dried under vacuum, and eluted with $5 \%$ formic acid in methanol, as described elsewhere. ${ }^{15}$

All eluates were collected and concentrated as described above, spiked with 50 or $100 \mathrm{ng}$ of internal standards, and adjusted to a final volume of $\sim 1 \mathrm{~mL}$ with methanol. The spiking recovery of drugs was also evaluated at more environmental relevant concentrations (spiking 2 or $4 \mathrm{ng}$ of target analytes) similarly as described above. A control sample spiked with internal standard mixture (but not spiked with the target drugs) was analyzed at the beginning and the end of the analysis of sample batch; the average concentrations of drugs in the blank (if any) were subtracted from the samples. At 2 or $4 \mathrm{ppb}$ spiking level, the absolute spiking recoveries of target NPSs using MCX and WCX ranged from $51.8 \pm 0.34 \%$ (4methylamphetamine) to $132 \pm 3.2 \%$ (MAB-CHMINACA) and $48.0 \pm 1.5 \%$ (4-methylamphetamine) to $128 \pm 0.90 \%$ (cyclopropyl fentanyl), respectively, whereas the absolute spiking recoveries of target NPSs using HLB and HLB-A ranged from $50.6 \pm 1.5 \%$ (4-methylamphetamine) to $115 \pm$ $3.4 \%$ (MAB-CHMINACA) and $50.6 \pm 4.0 \%$ (4-methylamphetamine) to $132 \pm 2.5 \%$ (cyclopropyl fentanyl), respectively (Figure 2). Overall, the triplicate spiking recoveries of target NPSs using MCX extraction cartridge found an optimum at both spiking levels; MCX was considered for the extraction of NPSs from the collected wastewater samples to determine their occurrence in communities. More details are provided in the SI.

Quality Assurance and Quality Control. Along with the analysis of sample extracts, a method blank and a matrix-spike sample $(n=2)$ were incorporated. A method blank consisted of acidified ultrapure water $(\mathrm{pH} \sim 2, \mathrm{HCl})$ spiked with 50 or $100 \mathrm{ng}$ of internal standards prior to extraction as described above. A random wastewater sample was considered for matrix-spike samples, spiked with 50 or $100 \mathrm{ng}$ of target analytes prior to extraction, and was processed as described above. As a calibration check standard, a mixture of standards at the midpoint calibration-level was analyzed after every 10 samples.

The method detection limit (MDL) was defined as the minimum concentration of an analyte that can be distinguished from the method blank and can be reported with 99\% confidence. $^{27}$ MDL was performed according to the U.S. Environmental Protection Agency's Code of Federal Regulations. ${ }^{27}$ Briefly, the wastewater samples $(100 \mathrm{~mL}, n=7)$ were acidified, centrifuged, filtered, and spiked with target drugs ( 0.1 or $0.2 \mathrm{ng}$ ) and internal standards (50 or $100 \mathrm{ng}$ ), and processed as described in Section 2.3. MDL was determined using the following equation:

$\mathrm{MDL}=\mathrm{s} \times t_{n-1,1-\alpha=0.99}$

where $\mathrm{s}$ is the standard deviations of the measured concentrations of a drug in seven replicate samples and $t$ is the Student's $t$ at $99 \%$ confidence level $(3.143$ for $n-1=6)$. The $95 \%$ confidence interval was estimated as

lower confidence limit $(\mathrm{LCL})=0.64 \times \mathrm{MDL}$

upper confidence limit $(\mathrm{UCL})=2.20 \times \mathrm{MDL}$

The limits of detection (LODs) and limits of quantification (LOQs) were defined as the calculated minimum concentration of analytes corresponding to the signal-to-noise ratio 3 and 10 , respectively, in wastewater extracts $(n=7)$ spiked with standards at the first calibration level ( 0.1 or $0.2 \mathrm{ng}$ ). A check standard was analyzed nine consecutive times for intraday repeatability as well as for nine consecutive days for the interday repeatability.

Mass Load Calculation. The mass load of NPSs was determined in four rural communities $(\mathrm{C} 1, \mathrm{C} 2, \mathrm{C} 3$, and $\mathrm{C} 4)$ in Southern Illinois based on the residual level of NPSs quantified in raw wastewater samples during a typical week with no special events using the following equation

$$
\text { massload }=\text { concentration }\left(\frac{\mathrm{ng}}{L}\right) \times \text { flowrate }\left(\frac{L}{d}\right) \times \frac{1 \mathrm{mg}}{1000000 \mathrm{ng}} \times \frac{1000}{\text { population }}
$$

where the mass load was expressed as $\mathrm{mg} / \mathrm{d} / 1000$ people, daily average wastewater inflow was considered, and the daily population served by the WWTP was determined based on a load of ammoniacal nitrogen in raw wastewater. The ammoniacal nitrogen was measured using a portable DR 
Table 1. Select Figure of Merits Including the Method Detection Limits (MDLs), Limits of Detection (LODs), Limits of Quantification (LOQs), and Repeatability

\begin{tabular}{|c|c|c|c|c|c|c|}
\hline analytes & $\begin{array}{l}\mathrm{MDL}(\mathrm{ng} / \\
\mathrm{L})\end{array}$ & $\begin{array}{l}\text { 95\% confidence interval } \\
(\mathrm{ng} / \mathrm{L})\end{array}$ & $\begin{array}{l}\text { LOD (ng/ } \\
\text { L) }\end{array}$ & $\begin{array}{c}\mathrm{LOQ}(\mathrm{ng} / \\
\mathrm{L})\end{array}$ & $\begin{array}{l}\text { intraday precision } \\
\qquad(n=9)^{a}\end{array}$ & $\begin{array}{l}\text { interday precision } \\
\quad(n=9)^{a}\end{array}$ \\
\hline \multicolumn{7}{|l|}{ Synthetic Opioids/Analgesics } \\
\hline carfentanil & 1.00 & $0.70-2.30$ & 0.50 & 1.50 & 0.71 & 1.16 \\
\hline furanyl fentanyl & 1.50 & $1.00-3.30$ & 0.90 & 3.20 & 0.30 & 0.76 \\
\hline valeryl fentanyl & 1.00 & $0.70-2.20$ & 0.10 & 0.20 & 0.50 & 0.58 \\
\hline butyryl fentanyl & 1.10 & $0.70-2.50$ & 0.30 & 0.90 & 0.68 & 0.85 \\
\hline acetyl fentanyl & 0.70 & $0.50-1.60$ & 0.10 & 0.40 & 0.36 & 0.92 \\
\hline cyclopropyl fentanyl & 0.90 & $0.60-2.00$ & 0.20 & 0.70 & 0.60 & 0.70 \\
\hline benzyl fentanyl & 0.90 & $0.60-2.00$ & 0.10 & 0.50 & 0.65 & 1.10 \\
\hline 3'-methyl fentanyl & 1.30 & $0.80-2.90$ & 0.10 & 0.30 & 0.53 & 0.48 \\
\hline 4'-methyl acetyl fentanyl & 0.80 & $0.50-1.70$ & 0.10 & 0.20 & 0.73 & 0.67 \\
\hline 4-fluoro-isobutyryl fentanyl & 1.30 & $0.80-2.80$ & 0.10 & 0.0 .20 & 2.19 & 0.32 \\
\hline para-fluorobutyryl fentanyl & 0.70 & $0.50-1.60$ & 6.60 & 22.0 & 1.14 & 0.61 \\
\hline methoxyacetyl fentanyl & 0.70 & $0.40-1.50$ & 0.10 & 0.20 & 0.58 & 0.73 \\
\hline 4-ANPP & 1.30 & $0.90-3.00$ & 0.40 & 1.20 & 0.66 & 1.22 \\
\hline U-48800 & 1.20 & $0.80-2.60$ & 0.10 & 0.30 & 0.69 & 1.10 \\
\hline U-47700 & 1.00 & $0.60-2.20$ & 0.30 & 1.00 & 0.44 & 0.67 \\
\hline \multicolumn{7}{|l|}{ Synthetic Cannabinoids } \\
\hline 5-fluoro MDMB-PICA & 1.00 & $0.60-2.20$ & 0.20 & 0.70 & 0.94 & 2.57 \\
\hline MAB-CHMINACA & 1.80 & $1.10-3.90$ & 6.30 & 21.0 & 4.19 & 3.29 \\
\hline MMB-FUBINACA & 2.90 & $1.90-6.40$ & 0.80 & 2.60 & 1.56 & 2.33 \\
\hline 5-fluoro EDMB-PINACA & 2.30 & $1.50-5.10$ & 0.10 & 0.40 & 1.98 & 2.93 \\
\hline (R)-5-fluoro $\mathrm{ADB}$ & 1.10 & $0.70-2.40$ & 0.40 & 1.20 & 1.60 & 1.09 \\
\hline AB-FUBINACA & 0.90 & $0.60-1.90$ & 2.20 & 7.30 & 2.09 & 1.62 \\
\hline MMB-CHMICA & 0.50 & $0.30-1.10$ & 0.20 & 0.60 & 0.66 & 1.47 \\
\hline AB-CHMINACA & 1.70 & $1.10-3.80$ & 1.30 & 4.20 & 2.04 & 2.02 \\
\hline ADB-FUBINACA & 0.90 & $0.50-1.90$ & 1.0. & 3.50 & 3.32 & 1.41 \\
\hline 5-fluoro AMB & 0.80 & $0.50-1.70$ & 0.20 & 0.50 & 1.05 & 1.38 \\
\hline NM2201 & 2.80 & $1.80-6.20$ & 0.40 & 1.30 & 1.37 & 2.98 \\
\hline \multicolumn{7}{|l|}{ Synthetic Cathinones } \\
\hline methcathinone & 1.20 & $0.80-2.70$ & 0.70 & 2.20 & 0.97 & 0.99 \\
\hline ethylone & 1.0. & $0.70-2.30$ & 0.30 & 1.00 & 0.33 & 0.67 \\
\hline 4-MMC (mephedrone) & 1.60 & $1.10-3.60$ & 1.00 & 3.30 & 0.78 & 3.15 \\
\hline 4-methyl pentedrone & 1.60 & $1.00-3.60$ & 2.40 & 7.80 & 1.73 & 2.04 \\
\hline$N$-ethylpentylone & 1.70 & $1.10-3.70$ & 2.30 & 7.70 & 0.38 & 0.81 \\
\hline$\alpha$-pyrrolidinopropiophenone & 1.50 & $1.00-3.30$ & 0.50 & 1.50 & 0.40 & 1.40 \\
\hline 3,4-methylenedioxypyrovalerone & 0.90 & $0.60-2.10$ & 0.40 & 1.40 & 0.45 & 0.76 \\
\hline$\alpha$-ethylaminohexanophenone & 1.40 & $0.90-3.20$ & 2.50 & 8.40 & 0.61 & 2.53 \\
\hline $\begin{array}{l}\text { 2-methyl-4'-(methylthio)-2- } \\
\text { morpholinopropiophenone }\end{array}$ & 0.60 & $0.40-1.30$ & 0.20 & 0.80 & 0.40 & 1.52 \\
\hline 4-chloro- $\alpha$-PVP & 1.30 & $0.90-2.90$ & 0.40 & 1.30 & 0.56 & 1.27 \\
\hline \multicolumn{7}{|l|}{ Piperazines } \\
\hline 1-(3-chlorophenyl) piperazine (mCPP) & 2.20 & $1.40-4.80$ & 0.90 & 2.90 & 1.93 & 1.80 \\
\hline $\begin{array}{l}\text { 1-cyclohexyl-4-(1,2-diphenylethyl) piperazine } \\
\text { (MT-45) }\end{array}$ & 0.80 & $0.50-1.90$ & 0.10 & 0.30 & 0.59 & 0.65 \\
\hline \multicolumn{7}{|l|}{ Indole } \\
\hline 5-(2-aminopropyl) Indole (5IT) & 3.30 & $2.10-7.20$ & 3.30 & 10.9 & 1.32 & 7.31 \\
\hline \multicolumn{7}{|l|}{ Amphetamine } \\
\hline 4-methylamphetamine & 6.30 & $4.10-13.9$ & 1.70 & 5.50 & 0.67 & 3.38 \\
\hline \multicolumn{7}{|l|}{ Anticonvulsants } \\
\hline clonazepam & 3.40 & $2.20-7.50$ & 1.90 & 6.30 & 0.78 & 1.61 \\
\hline gabapentin & 248 & $159-546$ & 3.40 & 11.2 & 1.64 & 2.45 \\
\hline
\end{tabular}

3900 spectrophotometer and Hach Company standard TNT plus method 10205 as

$$
P_{\mathrm{i}}=\frac{C_{\mathrm{NH} 4-\mathrm{N}} \times F_{i}}{R_{\mathrm{NH} 4-\mathrm{N}}} i=1,2,3, \ldots \ldots ., 7
$$

where $C_{\mathrm{NH} 4-\mathrm{N}}$ is the concentration of ammoniacal nitrogen $(\mathrm{mg} / \mathrm{L}), F_{\mathrm{i}}$ is the wastewater inflow $(\mathrm{L} / \mathrm{d})$ for the $i$ th day, and $R_{\mathrm{NH} 4-\mathrm{N}}$ is an average per-capita daily production of ammoniacal nitrogen $(6900 \mathrm{mg} / \mathrm{d}) .{ }^{6,28}$ The nonhuman sources of ammoniacal nitrogen could not be corrected; however, it is least affected by nonhuman sources compared to other 
Table 2. Average Concentration of Quantified NPSs in Raw Wastewater from Four Communities in Southern Illinois ${ }^{a}$

\begin{tabular}{|c|c|c|c|c|}
\hline analytes & $\mathrm{C} 1(\mathrm{ng} / \mathrm{L} \pm \mathrm{SE})$ & $\mathrm{C} 2(\mathrm{ng} / \mathrm{L} \pm \mathrm{SE})$ & $\mathrm{C} 3(\mathrm{ng} / \mathrm{L} \pm \mathrm{SE})$ & $\mathrm{C} 4(\mathrm{ng} / \mathrm{L} \pm \mathrm{SE})$ \\
\hline \multicolumn{5}{|l|}{ Synthetic Opioids } \\
\hline carfentanil & $1.9 \pm 0.1$ & $1.3 \pm 0.1$ & $0.5 \pm 0.1$ & $0.4 \pm 0.2$ \\
\hline furanyl fentanyl & $1.0 \pm 0.3$ & $0.6 \pm 0.3$ & $0.6 \pm 0.2$ & ND \\
\hline methoxyacetyl fentanyl & $<\mathrm{MDL}$ & $<\mathrm{MDL}$ & \pm 0.1 & $2.3 \pm 0.5$ \\
\hline \multicolumn{5}{|l|}{ Synthetic Cannabinoids } \\
\hline MAB-CHMINACA & $2.5 \pm 0.6$ & $4.0 \pm 0.9$ & $4.4 \pm 1.0$ & $0.6 \pm 0.3$ \\
\hline \multicolumn{5}{|l|}{ Synthetic Cathinones } \\
\hline methcathinone & $11.3 \pm 0.8$ & $17.8 \pm 1.3$ & $34.3 \pm 2.1$ & $16.9 \pm 2.6$ \\
\hline 4-methyl pentedrone & $5.3 \pm 0.3$ & $0.4 \pm 0.3$ & $0.7 \pm 0.2$ & $5.8 \pm 0.2$ \\
\hline MMMP & $1.6 \pm 0.1$ & $1.3 \pm 0.1$ & $0.9 \pm 0.1$ & $0.4 \pm 0.05$ \\
\hline \multicolumn{5}{|l|}{ Piperazine } \\
\hline $\mathrm{mCPP}$ & $56.4 \pm 2.7$ & $42.1 \pm 2.6$ & $10.3 \pm 0.3$ & $2.3 \pm 0.6$ \\
\hline \multicolumn{5}{|l|}{ indole } \\
\hline 5IT & $4.3 \pm 1.5$ & $3.6 \pm 1.4$ & $5.3 \pm 1.6$ & $19.2 \pm 6.3$ \\
\hline \multicolumn{5}{|l|}{ Anticonvulsant } \\
\hline gabapentin & $131,000 \pm 7600$ & $58,600 \pm 5100$ & $25,500 \pm 1150$ & $12,100 \pm 1370$ \\
\hline
\end{tabular}

${ }^{a}$ MDL: method detection limit; ND: non detected, MMMP: 2-methyl-4'-(methylthio)-2-morpholinopropiophenone; mCPP: 1-(3-chlorophenyl) piperazine; 5IT: 5-(2-aminopropyl) indole.
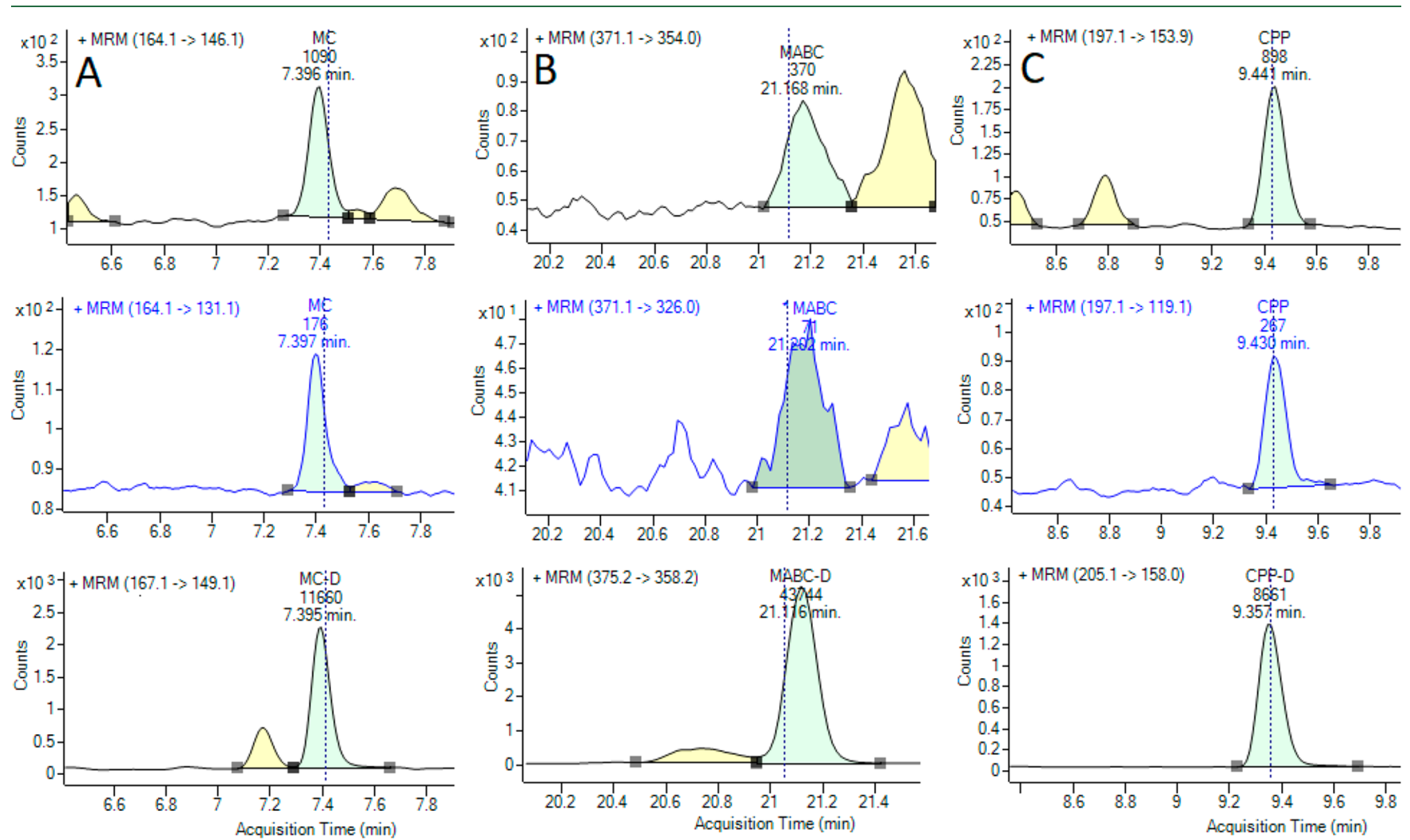

Figure 3. Representative chromatograms of selected drugs quantified in wastewater samples. (A) methcathinone; (B) MAB-CHMINACA; (C) $\mathrm{mCPP}$ [1-(3-chlorophenyl) piperazine]. The top chromatogram corresponds to the quantitative MS/MS transition; middle one corresponds to the qualitative MS/MS transition; and the bottom one corresponds to the internal standard.

conventional water-quality parameters including total nitrogen, total phosphorus, chemical oxygen demand, and chemical oxygen demand. ${ }^{28}$

\section{RESULTS AND DISCUSSION}

Figure of Merits. The average concentration of target drugs in method blanks were below the lowest calibration level; however, methcathinone and gabapentin were measured at 2.60 and $8.10 \mathrm{ng} / \mathrm{L}$, respectively. All reported concentrations hereby are blank-corrected. Analytical data points detected <
MDL were substituted with $1 / 2$ MDL values when the detection frequency is $\geq 70 \%$.

The average matrix-spiking recoveries (\%) of target analytes in a randomly selected wastewater sample $(n=2)$ ranged from $46.9 \%$ (NM 2201) to $164 \%$ (methoxyacetyl fentanyl). The spiking recovery of gabapentin could not be determined due to its higher background concentration ( $>16$ folds than the spiking level) in wastewater. Two (5IT and $3^{\prime}$-methyl fentanyl) of the 19 target drugs that were quantified using the internal standard of other analytes resulted in elevated spiking 
recoveries (201 and 254\%, respectively). The average percentage recoveries of target drugs from the calibration check standards that were analyzed along with the sample extracts ranged from $84.7 \%$ (5-IT) to $140 \%$ (mCPP); however, 4-methylamphetamine and 2-methyl-4'-(methylthio)-2-morpholinopropiophenone were recovered at $49.6 \%$ and $152 \%$, respectively.

The method detection limit of NPSs determined using seven replicates of the spiked sample matrix ranged from $0.5 \mathrm{ng} / \mathrm{L}$ (MMB-CHMICA) to $6.3 \mathrm{ng} / \mathrm{L}$ (4-methylamphetamine) (Table 1). LODs ranged from $0.1 \mathrm{ng} / \mathrm{L}$ (valeryl fentanyl) to $6.6 \mathrm{ng} / \mathrm{L}$ (para-fluorobutyryl fentanyl), whereas LOQs ranged from $0.2 \mathrm{ng} / \mathrm{L}$ (valeryl fentanyl) to $22.0 \mathrm{ng} / \mathrm{L}$ (parafluorobutyryl fentanyl) (Table 1). The interday precision expressed as a relative standard error of the measured concentrations of drugs from the repeated analysis of a check standard solution for nine consecutive days ranged from \pm 0.32 (4-fluoro-isobutyryl fentanyl) to \pm 7.31 (5IT) whereas the intraday precision for nine consecutive runs ranged from \pm 0.30 (furanyl fentanyl) to \pm 4.19 (MAB-CHMINACA) (Table 1).

Occurrence of NPSs in Wastewater. Nine NPSs were quantified in all four communities in Southern Illinois (Table 2, Figure 3). Methcathinone was the most frequently detected NPSs (frequency of detection, $\mathrm{df}=100 \%$ ) in all target communities followed by 2 -methyl-4' -(methylthio)-2-morpholinopropiophenone (a synthetic cathinone, $\mathrm{df}=91 \%$ ) and $\mathrm{mCPP}$ (piperazine, $\mathrm{df}=91 \%$ ). Methcathinone was reported as the most frequently detected NPS in wastewater across Australia ${ }^{23}$ and Italy. ${ }^{11}$ The concentration of methcathinone in this study was found $\sim 2-4$ folds higher than in Florence and $\sim 10-30$ folds higher than in Milan, Italy. ${ }^{11}$ 4-methyl pentedrone (a cathinone) was also detected in all samples from communities $\mathrm{C} 1$ and $\mathrm{C} 4$, whereas MAB-CHMINACA (a cannabinoid) was detected in communities C1, C2, and C3 in $>75 \%$ samples. Among synthetic opioids, carfentanil was detected in all samples from communities $\mathrm{C} 1$ and $\mathrm{C} 2$. Methoxyacetyl fentanyl and 5IT (an indole) were detected $>90 \%$ samples from community C4. Overall, methcathinone (11.3-34.3 ng/L) and $\mathrm{mCPP}(2.3-56.4 \mathrm{ng} / \mathrm{L})$ were more prevalent in target communities.

Estimation of the Population in WWTP Catchments. Wastewater based epidemiologists typically report mass loading of drugs $(\mathrm{mg} / \mathrm{d} / 1000$ people) to the WWTPs utilizing de jure population provided by the WWTP operators. However, de jure population does not account for the dynamicity in the population of the community. ${ }^{6,28} \mathrm{We}$ recently reported that the ammoniacal nitrogen-a biomarker of the population in the community-can account for the dynamicity in the population of the community and provide a near-accurate estimation of the population over the census population. ${ }^{6}$ Baz-Lomda et al. ${ }^{29}$ also reported that the population estimated based on ammoniacal nitrogen was found the best (mean absolute errors <10\%) anthropogenic proxy to determine the population of WWTP catchment area in Norway among other potential predictors such as drinking water production and electricity consumption. The ammoniacal based population estimation of Oslo was $>4 \%$ higher than the "de jure" population. ${ }^{29}$ In this study, the near-accurate population in WWTP catchments was determined using a load of ammoniacal nitrogen in raw wastewater (Table 3).

Mass Loading of NPS. The amount of NPS residues influx to the WWTP was determined and reported as the mass
Table 3. Estimated Population of Four Communities in Southern Illinois Based on a Load of Ammoniacal Nitrogen in Raw Wastewater

$\begin{array}{cccr}\text { communities } & \begin{array}{c}\text { census } \\ \text { estimation }^{a}\end{array} & \begin{array}{c}\mathrm{NH}_{4}-\mathrm{N} \\ (\mathrm{mg} / \mathrm{L})^{b}\end{array} & \begin{array}{c}\mathrm{NH}_{4}-\mathrm{N} \text {-based } \\ \text { population }^{b}\end{array} \\ \mathrm{C} 1 & 7882 & 23.2 \pm 1.9 & 9283 \pm 397 \\ \mathrm{C} 2 & 17620 & 21.1 \pm 2.1 & 19,597 \pm 799 \\ \mathrm{C} 3 & 20000^{c} & 10.3 \pm 0.5 & 16,253 \pm 976 \\ \mathrm{C} 4 & 2188 & 10.8 \pm 0.9 & 2980 \pm 239\end{array}$

${ }^{a}$ Census annual estimate of the resident population by the U.S. Census Bureau in 2018. ${ }^{b}$ Average \pm standard error. ${ }^{c}$ WWTP operator's estimation.

loading (mg/d/1000 people) (Figure 4). The mass load of methcathinone ranged from $2.98 \pm 0.17 \mathrm{mg} / \mathrm{d} / 1000$ people in

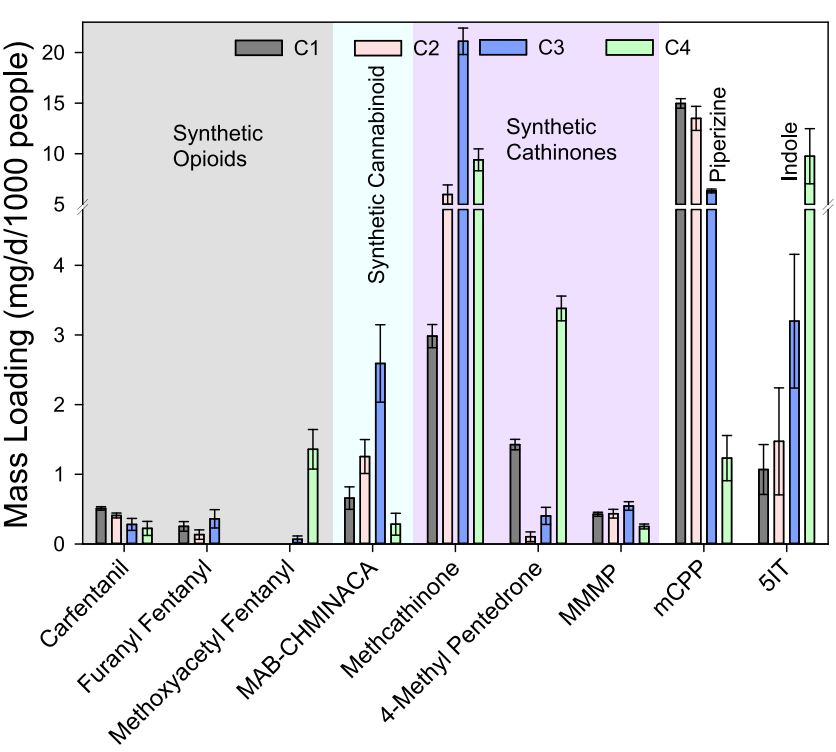

Figure 4. Average mass loading $(\mathrm{mg} / \mathrm{d} / 1000$ people) of quantified NPSs to the WWTPs in four rural communities in Illinois. MMMP: 2methyl-4'-(methylthio)-2-morpholinopropiophenone; mCPP: 1-(3chlorophenyl) piperazine; 5IT: 5-(2-aminopropyl) Indole.

$\mathrm{C} 1$ to $21.1 \pm 1.31 \mathrm{mg} / \mathrm{d} / 1000$ people in C3. Synthetic synthetic cathinones are among the most consumed NPSs ${ }^{11}$ and typically consumed as the "pure" form or "adulterants" in conventional illicit drugs, such as "ecstasy" pills. ${ }^{30}$ The actual amount of methcathinone consumed could be higher as synthetic cathinones undergo extensive metabolism in the human body ${ }^{15,31}$ as well as in-sewer transformation including the reduction of a $\beta$-keto group, demethylenation, and demethylation. $^{32}$

The mass load of the most prevalent cathinone (methcathinone) in community $\mathrm{C} 3$ was 3-7 folds higher than in $\mathrm{C} 1$ and $\mathrm{C} 2$, whereas the mass load of piperazine ( $\mathrm{mCPP}$ ) was $>2$ folds higher in $\mathrm{C} 1$ and $\mathrm{C} 2$ than in $\mathrm{C} 3$. The population is more diverse in community $\mathrm{C} 3$ including $~ 50 \%$ of college students than in community $\mathrm{C} 1$ and $\mathrm{C} 2$. $\mathrm{mCPP}$ was prevalent in all target communities $(1.23 \pm 0.32$ to $15.0 \pm 0.5 \mathrm{mg} / \mathrm{d} / 1000$ people) in this study. Causanilles et al. ${ }^{21}$ reported mCPP qualitatively in wastewater during a street festival in Amsterdam, Netherland. mCPP was not detected across China; however, benzylpiperazine was prevalent at 3-10 $\mathrm{mg} / \mathrm{d} / 1000$ people. $^{22}$ To our knowledge, this is the first quantitative report of $\mathrm{mCPP}$ in wastewater. 
SIT (a stimulant, $9.75 \pm 2.72 \mathrm{mg} / \mathrm{d} / 1000$ people) and 4methyl pentedrone (a cathinone, $3.38 \pm 0.18 \mathrm{mg} / \mathrm{d} / 1000$ people), and methoxyacetyl fentanyl $(1.36 \pm 0.28 \mathrm{mg} / \mathrm{d} / 1000$ people), were more prevalent in community C4. NPSs are also considered a cheap-substitute of conventional drugs of abuse; therefore, more prevalent in socially marginalized communities. ${ }^{10}$ Community $\mathrm{C} 4$ is relatively a socially marginalized community with $>30 \%$ residents below the poverty line. The mass load of MAB-CHMINACA, the only cannabinoid quantified, was up to $2.59 \pm 0.56 \mathrm{mg} / \mathrm{d} / 1000$ people in community C3. To our knowledge, this is the first quantitative report of MAB-CHMINACA in wastewater. In a nationwide survey among 45400 high school senior students, synthetic cannabinoids were the third most widely abused class of drugs in the U.S. ${ }^{33}$ The carfentanil was the only synthetic opioid quantified in all wastewater samples in community $\mathrm{C} 1(0.51 \pm$ $0.03 \mathrm{mg} / \mathrm{d} / 1000$ people $)$ and $\mathrm{C} 2(0.41 \pm 0.04 \mathrm{mg} / \mathrm{d} / 1000$ people). Carfentanil is $\sim 100$ folds more potent than fentanyl. The occurrence of carfentanil in this study ( $\mathrm{C} 1$ and $\mathrm{C} 2$ ) was $\sim 300$ folds lower than the occurrence of fentanyl $(152 \mathrm{mg} / \mathrm{d} /$ 1000 people) in two communities in adjoined state of Kentucky.

Unlike established illicit or prescribed drugs of potential abuse, the pharmacokinetic profiles of most of the NPS's excretion are still unknown. ${ }^{11,34}$ As a result, all quantitative WBE studies are limited to reporting the mass loading of NPSs to the WWTPs. The near-accurate estimation of the prevalence of NPSs would require to normalize mass load with the excretion rate of target NPSs (or their stable metabolites), the stability of NPS biomarkers in wastewater, and the typical does of the NPSs. To our knowledge, no wastewater stability data are available of target NPSs; however, only one study reported methcathinone's human excretion rate of $36 \%$ as a parent drug. ${ }^{35}$ The excretion rate corrected mass load of methcathinone were $8.29 \pm 0.46 \mathrm{mg} / 1000$ people, $16.6 \pm 2.63 \mathrm{mg} / 1000$ people, $58.6 \pm 3.63 \mathrm{mg} / 1000$ people, and $26.1 \pm 3.00 \mathrm{mg} /$ 1000 people at the target communities $\mathrm{C} 1, \mathrm{C} 2, \mathrm{C} 3$, and $\mathrm{C} 4$, respectively. Further study on the pharmacokinetic profiles of the NPSs execration as well as the stability of NPSs in sewer networks and the wastewater samples is inevitable to determine the prevalence of community consumption of NPSs.

\section{ASSOCIATED CONTENT}

\section{(I) Supporting Information}

TThe Supporting Information is available free of charge at https://pubs.acs.org/doi/10.1021/acs.est.0c00250.

Mobile phase compositions and programming, optimized MS/MS transitions and collision energies of target drugs, chromatograms showing drugs' chromatographic separation, optimized extraction efficiency, and the prevalnce of gabapentin in target communities (PDF)

\section{AUTHOR INFORMATION}

\section{Corresponding Author}

Bikram Subedi - Department of Chemistry, Murray State University, Murray, Kentucky 42071-3300, United States; (1) orcid.org/0000-0001-7832-2585; Phone: 1-270-8096542; Email: bsubedi@murraystate.edu; Fax: 1-270-8096474

\section{Author}

Catherine E. O'Rourke - Department of Chemistry, Murray State University, Murray, Kentucky 42071-3300, United States

Complete contact information is available at:

https://pubs.acs.org/10.1021/acs.est.0c00250

\section{Notes}

The authors declare no competing financial interest.

\section{ACKNOWLEDGMENTS}

We are thankful to The Jones/Ross Research Center at the Department of Chemistry, Murray State University for providing access to the UPLC-MS/MS. We grealty appreciate Dr. Wiley Jenkin and Mr. Brent van Ham for invaluable assistance on sample collections. The wastewater treatment plant is acknowledged for providing wastewater samples. This study was funded by grants from the Kentucky Biomedical Research Infrastructure Network (Grant\# NIGMS 8P20GM103436) and The Committee On Institutional Studies and Research (CISR) at Murray State University.

\section{REFERENCES}

(1) NIDA (National Institute on Drug Abuse), 2018. Synthetic Cathinones "Bath Salts. https://www.drugabuse.gov/publications/ drugfacts/synthetic-cathinones-bath-salts (accessed 2020/1/10).

(2) UNODC (United Nations Office On Drugs and Crime), 2019. World Drug Report 2019. Available at https://wdr.unodc.org/ wdr2019/index.html (accessed 2020/1/10).

(3) NDEWS (National Drug Early Warning System), 2019. Emerging Threat Report - Mid-Year 2019. https://ndews.umd. edu/sites/ndews.umd.edu/files/Emerging-Threat-Report-2019-MidYear.pdf (accessed 2020/1/10).

(4) NDEWS (National Drug Early Warning System), 2018. Top 25 Most Frequently Identified Drugs by Year. https://data.ndews.org/ nflis/national-regional/national-estimates-top-25/ (accessed 2020/1/ 10).

(5) NDEWS (National Drug Early Warning System), 2017. Drug Category by State and Year. https://data.ndews.org/nflis/state-level/ drug-category-by-state-and-year/ (accessed 2020/1/10).

(6) Croft, T. L.; Huffines, R. A.; Pathak, M.; Subedi, B. Prevalence of illicit and prescribed neuropsychiatric drugs in three communities in Kentucky using wastewater-based epidemiology and Monte Carlo simulation for the estimation of associated uncertainties. J. Hazard. Mater. 2020, 384, 121360.

(7) Foppe, K. S.; Weinberger, D.; Subedi, B. Estimation of the consumption of illicit drugs during special events in two communities in Western Kentucky, USA. Sci. Total Environ. 2018, 633, 249-256.

(8) Subedi, B.; Burgard, D. A.; Loganathan, B. G. (Eds). Wastewaterbased Epidemiology: Estimation of Community Consumption of Drugs and Diets. ACS Symposium Series 1319; American Chemical Society: Washington, DC, 2019.

(9) Bade, R.; Stockham, P.; Painter, B.; Celma, A.; Bijlsma, L.; Hernandez, F.; White, J. M.; Gerber, C. Investigating the Appearance of New Psychoactive Substances in South Australia using Wastewater and Forensic Data. Drug Test. Anal. 2019, 2, 250-256.

(10) Peacock, A.; Bruno, R.; Gisev, N.; Degenhardt, L.; Hall, W.; Sedefov, R.; White, J.; Thomas, K. V.; Farrell, M.; Griffiths, P. New psychoactive substances: challenges for drug surveillance, control, and public health responses. Lancet 2019, 394, 1668-1684.

(11) Gonzalez-Marino, I.; Gracia-Lor, E.; Rousis, N. I.; Castrignano, E.; Thomas, K. V.; Quintana, J. B.; Kasprzyk-Hordern, B.; Zuccato, E.; Castiglioni, S. Wastewater-based epidemiology to monitor synthetic cathinones use in different European countries. Environ. Sci. Technol. 2016, 50, 10089-10096. 
(12) Cohen, K.; Weinstein, A. M. Synthetic and non-synthetic cannabinoid drugs and their adverse effects $-\mathrm{A}$ review from public health perspectives. Front. Public Health 2018, 6, 162-170.

(13) Borova, V. L.; Gago-Ferrero, P.; Pistos, C.; Thomaidis, N. S. Multi-residue determination of 10 selected new psychoactive substances in wastewater samples by liquid chromatography-tandem mass spectrometry. Talanta 2015, 144, 592-603.

(14) Gonzalez-Marino, I.; Gracia-Lor, E.; Bagnati, R.; Martins, C. P. B.; Zuccato, E.; Castiglioni, S. Screening new pshychaocativ esusbtances in urban wastewater using high resolution mass spectromtery. Anal. Bioanal. Chem. 2016, 408, 4297-4309.

(15) Celma, A.; Sancho, J. V.; Salgueiro-González, N.; Castiglioni, S.; Zuccato, E.; Hernández, F.; Bijlsma, L. Simultaneous determination of new psychoactive substances andillicit drugs in sewage: Potential of micro-liquid chromatography tandem mass spectrometry in wastewater-based epidemiology. J. Chromatogr. A 2019, 1602, 300-309.

(16) Fontanals, N.; Marcé, R. M.; Borrull, F. Solid-phase extraction followed by liquid chromatography-high resolution mass spectrometry to determine synthetic cathinones indifferent types of environmental water samples. J. Chromatogr. A 2017, 1524, 66-73.

(17) Salgueiro-González, N.; Castiglioni, S.; Gracia-Lor, E.; Bijlsma, L.; Celma, A.; Bagnati, R.; Hernández, F.; Zuccato, E. Flexible high resolution-mass spectrometry approach for screening new psychoactive substances in urban wastewater. Sci. Total Environ. 2019, 689, 679-690.

(18) Campos-Mañas, M. C.; Ferrer, I.; Thurman, E. M.; SánchezPérez, J. A.; Agüera, A. Identification of opioids in surface and wastewaters by LC/Q-TOF-MS using retrospective data analysis. Sci. Total Environ. 2019, 664, 874-884.

(19) Campos-Mañas, M. C.; Ferrer, I.; Thurman, E. M.; Agüera, A. Opioid occurrence in environmental water samples - a review. Trends Environ. Anal. Chem. 2018, 20, e00059.

(20) Ibanez, M.; Sancho, J. V.; Bijlsma, L.; van Nuijs, A. L. N.; Covaci, A.; Hernandez, F. Comprehensive analytical strategies based on high-resolution time-of-flight mass spectrometry to identify new psychoactive substances. TrAC, Trends Anal. Chem. 2014, 57, 107117.

(21) Causanilles, A.; Kinyua, J.; Ruttkies, C.; van Nuijs, A. L. N.; Emke, E.; Covaci, A.; de Voogt, P. Qualitative screening for new psychoactive substances in wastewater collected during a city festival using liquid chromatography coupled to high-resolution mass spectrometry. Chemosphere 2017, 184, 1186-1193.

(22) Gao, T.; Du, P.; Xu, Z.; Li, X. Occurrence of new psychoactive substances in wastewater of major Chinese cities. Sci. Total Environ. 2017, 575, 963-969.

(23) Bade, R.; Tscharke, B. J.; White, J. M.; Grant, S.; Mueller, J. F.; O'Brien, J.; Thomas, K. V.; Gerber, C. LC-HRMS suspect screening to show spatial patterns of new psychoactive substances use in Australia. Sci. Total Environ. 2019, 650, 2181-2187.

(24) Bade, R.; Bijlsma, L.; Sancho, J. V.; Baz-Lomba, J. A.; Castiglioni, S.; Castrignan, E.; Causanilles, A.; Gracia-Lor, E.; Kasprzyk-Hordern, B.; Kinyua, J.; McCall, A. K.; van Nuijs, A. L. N.; Ort, C.; Plosz, B. G.; Ramin, P.; Rousis, N. I.; Ryu, Y.; Thomas, K. V.; de Voogt, P.; Zuccato, E.; Hernandez, F. Liquid chromatographytandem mass spectrometry determination of synthetic cathinones and phenethylamines in influent wastewater of eight European cities. Chemosphere 2017, 168, 1032-1041.

(25) Evoy, K. E.; Covvey, J. R.; Peckham, A. M.; Ochs, L.; Hultgren, K. E. Reports of gabapentin and pregabalin abuse, misuse, dependence, or overdose: An analysis of the food and drug administration adverse events reporting system (FAERS). Res. Social Admin. Pharm. 2019, 15, 953-958.

(26) Waters, 2019. Oasis Sample Extraction Products. https://www. waters.com/waters/en US/Waters-Oasis-Sample-Extraction-SPEProducts $/$ nav.htm?cid $=513209 \&$ locale $=$ en_US (accessed 2020/1/ $10)$.

(27) USEPA (United States Environmental Protection Agency). Definition and Procedure for the Determination of the Method
Detection Limit, Code of Federal Regulations, Title 40, Section 136, Appendix B, 1986.

(28) Been, F.; Rossi, L.; Ort, C.; Rudaz, S.; Delémont, O.; Esseiva, P. Population normalization with ammonium in wastewater-based epidemiology: application to illicit drug monitoring. Environ. Sci. Technol. 2014, 48, 8162-8169.

(29) Baz-Lomba, J. A.; Ruscio, F. D.; Amador, A.; Reid, M.; Thomas, K. V. Assessing alternative population size proxies in a wastewater catchment area using mobile device data. Environ. Sci. Technol. 2019, 53, 1994-2001.

(30) Hondebrink, L.; Lonkhuyzen, J. J. N.; Gouwe, D. V. D.; Brunt, T. M. Monitoring new psychoactive substances (NPS) in The Netherlands: Data from the drug market and the poisons information center. Drug Alcohol Depend. 2015, 147, 109-115.

(31) Chen, C.; Kostakis, C.; Irvine, R. J.; White, J. M. Increases in use of novel synthetic stimulant are not directly linked to decreased use of 3,4-methylenedioxy-N methylamphetamine (MDMA). Forensic Sci. Int. 2013, 231, 278-283.

(32) Kinyua, J.; Negreira, N.; McCall, A. K.; Boogaerts, T.; Ort, C.; Covaci, A.; van Nuijs, A. L. N. Investigating in-sewer transformation products formed from synthetic cathinones and phenethylamines using liquid chromatography coupled to quadrupole time-of-flight mass spectrometry. Sci. Total Environ. 2018, 634, 331-340.

(33) Johnston, L. D.; O’Malley, P. M.; Bachman, J. G.; Schulenberg, J. E. Monitoring the Future national results on drug use: 2012 Overview, Key Findings on Adolescent Drug Use www. monitoringthefuture.org/pubs/monographs/mtf-overview2012.pdf (accessed 2020/3/7).

(34) Reid, M. J.; Derry, L.; Thomas, K. V. Analysis of new classes of recreational drugs in sewage: synthetic cannabinoids and amphetamine-like substances. Drug Test. Anal. 2014, 6, 72-79.

(35) Markantonis, S. L.; Kyroudis, A.; Beckett, A. H. The sterioslective metabolism of dimethylpropion and monomethylpropion. Biochem. Pharmacol. 1986, 35, 529-532. 